\title{
XXXIV. On the velocity of the electrical wave or current through a metallic circuit
}

\section{O.M. Mitchel}

To cite this article: O.M. Mitchel (1850) XXXIV. On the velocity of the electrical wave or current through a metallic circuit, Philosophical Magazine Series 3, 36:243, 284-290, DOI: $10.1080 / 14786445008646475$

To link to this article: http://dx.doi.org/10.1080/14786445008646475

册 Published online: 30 Apr 2009.

Submit your article to this journal $\sqsubset \pi$

Џ Article views: 2

Q View related articles $\square$ 


\section{[284]}

XXXIV. On the Velocity of the Electrical Wave or Current through a Metallic Circuit. By O. M. Mitches, Director. of the Cincinnati Observatory*.

THE machinery now in use in the Cincinnati Observatory, 1 for the conversion of time into space, furnishes the means of executing the most delicate experiments in the record of minute fractions of time. The sidereal clock is made to record its beats on a metallic disc, revolving beneath a steel recording pen fixed in position. The disc which carries the metal plate is made to revolve with uniform velocity, and receives the stroke of the recording pen without affecting its motion. A second pen, situated directly opposite the first, is placed under the control of the observer at the transit or other instrument, and gives him the means of recording any observed phænomenon with all the accuracy with which the eye can seize the instant of its occurrence.

On the completion of this machinery, several months since, my attention was called to the velocity of electrical currents in their passage along the telegraphic wires and through the ground, as being involved in the determination of differences of longitude by signals, transmitted telegraphically.

On the evening of the 12th of November, a series of experiments was performed at the Observatory, to determine the velocity of the electrical wave in its passage along the telegraphic wires. The long circuit involved in these experiments was formed as follows:-

From the main battery in the O'Rielly Telegraph Office, Cincinnati, along one wire to the observatory, a distance of one mile; thence, by the continuation of the same wire, to Pittsburg; thence, returning on a second wire, to the observatory; thence, through the receiving magnet, to a ground wire; thence, one mile, through the ground, to the main battery in Cincinnati.

The following is the plan on which the experiments were conducted. The sidereal clock was so arranged that its pendulum closed a local circuit, operating on the time-pen and recording the alternate clock-beats or seconds, on a metal plate placed on the revolving disc already described. This connexion remained unchanged during the entire course of the experiments, and this pen is called hereafter the standard pen.

A receiving magnet was made to close a short local circuit (equal in power and length to the former), which operated on the observation pen, causing it to strike its point into the metal

* From the American Astronomical Journal, No. 2, December 13, 1849. 
plate. This receiving magnet was operated on in two modes, at the pleasure of the experimenter, as follows :-

1. By a local circuit, which was closed by the metallic handle of the standard pen.

2. By the long circuit before described, passing to and from Pittsburg, a distance of 607 miles, along the wires.

By these connexions, it will be seen that the clock-beats were directly recorded by the standard pen. They were also recorded by the variable pen (as I shall designate the second one), moved by the standard pen, closing either a short local circuit through the receiving magnet, or the long Pittsburg circuit, through the same receiving magnet,-this receiving magnet, as before stated, closing the local circuit operating on the variable pen.

The standard pen record was followed by the variable pen record, at an interval in time equal to the armature time of the standard pen, increased by the armature time of the receiving magnet, increased by the wave time of the fluid in passing through the short circuit and receiving magnet, this last being of course insensible. This statement applies when the variable pen is driven by the short local circuit.

When the long circuit operates on the receiving magnet, and through this on the variable pen, then the standard pen is followed by the variable pen at an interval identical with the preceding, increased by the time required by the electrical wave or current for traversing the wires 607 miles. viz.-

This statement is only true on the following conditions,

1. The intensity of the local circuit and the long circuit must be reduced to equality.

2. The adjustment of the receiving magnet must be constant, and its pass must be reduced to a minimum.

These two conditions being fulfilled, in case the two pens are so adjusted to each other in position that a straight line joining any two corresponding dots struck by them on a disc at rest will pass through the centre of the disc, then the interval between the records of the two pens driven by a short and long circuit, diminished by the interval between the records when the variable pen is driven by a short circuit, will exhibit the time occupied by the wave in traversing the distance of 607 miles through the wires.

I will now proceed to show the importance of fulfilling strictly these three conditions:-

1. To adjust to equality the intensity of the long and short circuits operating through the receiving magnet upon the variable pen. 
2. To reduce the pass of the receiving magnet to a minimum, and to keep it unchanged.

3. To adjust the recording pens to exact radiation of records, the disc being quiescent.

To ascertain the effect of intensity and pass, the following experiments were performed. The connexions having been made as above described, four circumferences of second-dots were recorded by the two pens, under the following circumstances :-

No. 1. The pass of the receiving magnet a minimum.

No. 2. The pass of the receiving magnet a maximum.

No. 3. The battery reduced to one-half its former power, the pass a maximum.

No. 4. The reduced battery, the pass a minimum.

On circumference No. 1,-minimum pass, and strong battery, - the variable pen fell behind the standard pen $0^{\text {s. }} 091$ on a mean of many measures. The uniformity of these records and the accuracy of the measures are best exhibited by the measures themselves. I give as a specimen the first ten measures out of thirty:-

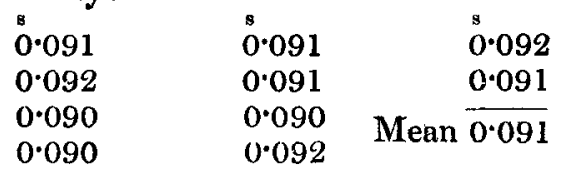

On circumference No. 2,-maximum working pass, strong battery, - the same interval became $0^{\mathrm{s}} \cdot 2628$.

Circumference No. 3,-battery reduced one-half, maximum pass, - the same interval measured $0^{\mathrm{s}} \cdot 310$.

Circumference No. 4, - weak battery, pass a minimum,same interval measured $0^{5} \cdot 104$.

From these experiments, it becomes manifest that the adjustment of the receiving magnet may give variations of record far greater than the anticipated value of wave time on the longest available circuit. It is further shown, that the effect of different intensities is such as to entail an error so great as to render all experiments useless, from which this effect is not strictly eliminated.

Two difficulties were now to be overcome. The batteries must be reduced to equality, and the evidence of that equality must be obtained. The following plan was adopted to accomplish these objects. The handles of the recording pens are flexible, and vibrate at every stroke of the pen. Half the length of this vibration is the armature time, as I will show hereafter. Now the armature time was found to depend on the intensity of the currents which operated on the receiving 
magnet. The local battery was therefore increased or decreased in power until the armature time, as recorded by the two circuits, was identical in value; - the pen being so adjusted that the primary dot was always followed by the second, or vibrating dot, which was distinctly recorded by the pen in every record made.

These difficulties being thus overcome, the pens were adjusted to produce radiating dots, the disc being quiescent. It was subsequently found that this adjustment was imperfect to eleven thousandths of a second of time on the greatest circumference recorded. The absolute space was laid off on all the remaining circumferences, and, being accurately measured, gives the required correction.

All the arrangements having been perfected, the local connexions were placed in the care of Mr. Henry Twitchell, while it was assisted in the distant connexions by Mr. Stager, of the O'Rielly 'Telegraph Office, Cincinnati.

The evening was fair and calm, warm for the season. Mr. Stager reported the line in admirable working order. 'The receiving magnet was adjusted to its minimum working pass, and the long and short circuit batteries were pronounced equal in strength, by the equality of the recorded armature times.

At $9^{\mathrm{h}} 58^{\mathrm{m}}$ the pens fell together on the metal plate, the variable pen being operated on by the long circuit. I watched the disc to see that the records were perfectly made. The dots came down in the most beautiful manner, and the record was engraved on the metal with exquisite delicacy. At the close of the first circumference of dots, occupying exactly sixty seconds, notice was given to change; and, at the word, the long circuit was thrown off, and the local short circuit took its place. This change was so skilfully accomplished by $\mathrm{Mr}$. Stager, that not a second was lost.

In this way five complete circumferences were recorded,three with the long, and two with the short circuit. The ear could sometimes with difficulty recognize the change from long to short; but after many trials it was found that this organ could not with certainty be relied on. 'The conversion of time into space on the disc gave us, however, the opportunity of bringing a high magnifying power to bear upon the reading of the delicate records.

Mr. Twitchell has completed all the measures with the instrument contrived by me for measuring small angular spaces. It can be read down to the thousandth of a second of time. The disc performed in the most admirable manner during the entire experiment, the records radiating from its centre, and demonstrating the uniformity of its motion.

I present the measures of circumferences Nos. 1 and 2, to 
exhibit the character of the records. The slight variations are due, doubtless, to want of absolute uniformity in the connexions. The variations are, however, very slight, and disappear in the mean of a group of thirty observations. The measures follow.

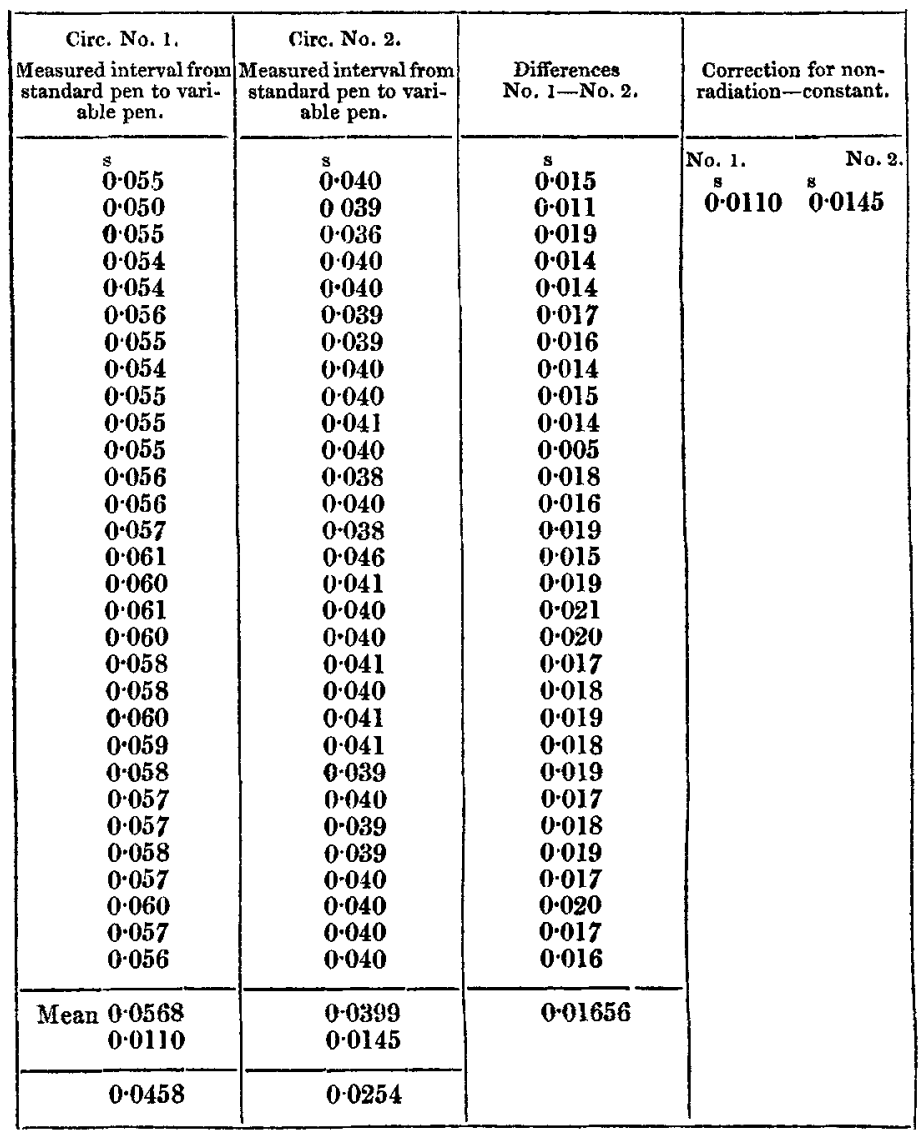

The mean values of the intervals are as follows:-

Correction for non-radiation.

s s s

No. 1 , long circuit, interval $=0.0568-0.0110=0.0458$

No. 2, short $\quad \ldots \quad=0.0399-0.0145=0.0254$

No. 3, long $\quad \ldots \quad=0.0633-0.0165=0.0468$

No. 4, short $\quad \ldots \quad=0.0444-0.0195=0.0249$

No. 5, long $\quad \ldots \quad=0.0682-0.0215=0.0467$ 
Electrical Wave or Current through a Metallic Circuit. 289

From a comparison of these values we obtain-

$$
\begin{aligned}
& \text { No. } 1 \text {, long circuit . . . . }=0.0458 \\
& \text { No. 2, short circuit . . . . }=0.0254 \\
& \text { Wave time on } 607 \text { miles of wire }=\overline{0.0204} \\
& \text { No. } 1 \text {. . . . . . }=0.0458 \\
& \text { No. 4. . . . . . . }=0.0249 \\
& \text { Wave time . . . . . }=\overline{0.0209} \\
& \text { No. } 3 \text {. . . . . . . }=0.0468 \\
& \text { No. } 2 \cdot . \cdot \cdot \cdot \cdot \cdot \cdot=0.0254 \\
& \text { Wave time . . . . . }=\overline{0.0214} \\
& \text { No. } 3 \text {. . . . . . },=0.0468 \\
& \text { No. } 4 . \cdot . \cdot . \cdot . \quad \cdot=0.0249 \\
& \text { Wave time } \cdot . \cdot . \cdot .=\overline{0}=0.0219 \\
& \text { No. } 5 \text {. . . . . . . }=0.0467 \\
& \text { No. } 2 \text {. . . . . . }=0.0254 \\
& \text { Wave time . . . . . . }=\overline{0.0213} \\
& \text { No. } 5 \text {. . . . . . . }=0.0467 \\
& \text { No. 4. . . . . . . }=0.0249 \\
& \text { Wave time . . . . . . }=\overline{0.0218}
\end{aligned}
$$

Wave time on 607 miles of wire, as deduced from-

$$
\begin{array}{r}
\text { No. } 1-\text { No. } 2=0.0204 \\
\text { No. } 1-\text { No. } 4=0.0209 \\
\text { No. } 3-\text { No. } 2=0.0214 \\
\text { No. } 3-\text { No. } 4=0.0219 \\
\text { No. } 5-\text { No. } 2=0.0213 \\
\text { No. } 5-\text { No. } 4=0.0218 \\
\text { Mean }=0.02128 \\
\text { Mean } \pm \text { No. } 1=0.00088 \\
\text { Mean } \pm \text { No. } 2=0.00038 \\
\text { Mean } \pm \text { No. } 3=0.00014 \\
\text { Mean } \pm \text { No. } 4=0.00064 \\
\text { Mean } \pm \text { No. } 5=0.00002 \\
\text { Mean } \pm \text { No. } 6=0.00052 \\
\text { Mean }=0.00043
\end{array}
$$

That is, the mean difference from the mean amounts to 43 hundred-thousandths of a second of time.

The velocity deduced along the wires, in case the circuit is 607 miles in length, is 28524 miles per second.

At some future time I hope to resume these investigations. It would be interesting to repeat these experiments at differ- 
ent hours of the day and night, at different seasons of the year, and through different media. May not the velocity through the ground vary with the direction of the current, - whether east and west, or north and south?

I place great confidence in these results, as every care was taken to eliminate all possible sources of error. Every magnet in use was in the observatory, and all the connexions and adjustments were under my own eye.

The adjustment of the receiving magnet was unaltered during the experiment, and no change occurred for more than thirty minutes after the experiments were finished. Each of the pens recorded, in every instance, the armature time in the distance from the primary to the vibratory dot. One-half this record was shown to be the armature time, as follows :-

The variable pen could not begin to descend until the standard pen was down. Hence, considering the armature time of the receiving magnet as insensible (as it was), with a short circuit the interval of the two records would be equal to the armature time of the standard pen. This interval, being measured, was found to be exactly one-half the interval between the primary and vibratory dot of the standard pen.

The length of this article forbids me to go into further detail. In case further particulars are desired, it will give me pleasure to furnish them by correspondence, or by a further publication.

Cincinnati Observatory,

November 16, 1849 .

XXXV. On the True Amplitude of a Tessarine; on the Derivation of the word 'Theodolite; and on Light under the action of Magnetism. By JaMes CockLE, Esq., M.A., of Trinity College, Cambridge, Barrister-at-larv*.

A NY tessarine $w+i^{\prime} x+j^{\prime} y+k^{\prime} z$, or $t$, may be put under the form $t$

$$
\mathbf{M}\left\{q \cos p+i^{\prime} r \sin p+\jmath^{\prime}(1-q) \cos p+k^{\prime}(1-r) \sin p\right\},
$$

* Communicated by the Author. Mr. Cockle takes an opportunity of stating that remarks on the Tessarine Theory, as well as on the impossible equations and quantities so intimately connected with it, will be found in his Hore Algebraice, published in vols. xlvii. to l. of the Mechanics' Magazine; and he also begs to refer the reader to the following papers published in the same work, and in which he has adverted to the same subject; viz. "On Algebraic Symbols," Mechanics" Magazine, vol. I. pp. 292-294; "On the Symbols of Algebra, and on the T'heory of Tesssarines," Ibid. p. 534; "On the Tessarine Algebra," Ibid. Pp. 558, 559; "On certain Researches of Mr. Buole, and the Symbol of Infinity," Ibid. vol.li. pp. 124, 125; "On Systems of Quadruple Algebra," lbid. pp. 197-199; and see some further remarks " On Quadruple Algebra," Ibid. vol. li, pp. 557, 558; and "On Tessarines," Ibid. p. 610.

+ See Mechanics' Magazine, vol. li. p. 610. 